\title{
A comparative study between manual vacuum aspiration and electrical vacuum aspiration for the first trimester medical termination of pregnancy
}

\author{
Sunil K. Samal, Setu Rathod*, Maya Padhi \\ Department of Obstetrics \& Gynecology, SCB Medical College, Cuttack - 753007, Odisha, India
}

Received: 8 January 2014

Accepted: 2 February 2014

*Correspondence:

Dr. Setu Rathod,

E-mail: seturathod@gmail.com

(C) 2014 Samal SK et al. This is an open-access article distributed under the terms of the Creative Commons Attribution Non-Commercial License, which permits unrestricted non-commercial use, distribution, and reproduction in any medium, provided the original work is properly cited.

\begin{abstract}
Background: The aim of this study is to compare the manual vacuum aspiration (MVA) and electrical vacuum aspiration (EVA) as the method for first trimester medical termination of pregnancy (MTP) in terms of efficacy, blood loss, duration, acceptability and complications. The study also compares paracervical block (PCB) and intramuscular sedation (IMS) i.e., injection pentazocine $30 \mathrm{mg}$ and injection promethazine $25 \mathrm{mg}$ as pre-operative analgesia for both the MTP procedures.

Methods: The present study was conducted in the postpartum center and department of Gynecology and Obstetrics, SCB Medical College, Cuttack. A total 200 patients were studied of which randomly selected 100 patients underwent MVA and remaining 100 patients underwent EVA. Cases were compared with respect to their age, parity, blood loss, time taken and complications.

Results: In the present study, MVA was effective in $97 \%$ and EVA in $98 \%$ cases. Thus, the two procedures did not show much difference as far as their effectiveness was concerned. Comparing intra and post-operative pain, PCB was significantly more effective in reducing pain as compared to IMS.

Conclusions: MVA has a safety and efficacy profile similar to that of EVA. Furthermore, MVA is a simple, safe, effective procedure, portable and low cost technique. Hence, MVA is a promising method compared to EVA and can be practiced widely in rural areas where access to medical facilities are limited, high-tech equipments were not available and the power supply was erratic and maintenance of instruments were not up to the mark. The judicious use of MVA comes with a promise to make early abortions safe and easily accessible to women of both rural and urban societies belonging to any socio-economic strata.
\end{abstract}

Keywords: Manual vacuum aspiration, Electrical vacuum aspiration, Abortion, Paracervical block

\section{INTRODUCTION}

Unsafe abortion is a neglected women's health issue in India wherein there are approximately 10,000 to 12,000 deaths each year due to abortion related complications. ${ }^{1}$ Unsafe abortion is defined by the World Health Organization (WHO) as "a procedure for terminating an unwanted pregnancy either by persons lacking the necessary skills or in an environment lacking the minimal medical standards, or both" (WHO 1992). ${ }^{2}$ World-wide, 42 million pregnancies each year end in abortion, with 19.7 million of these abortions taking place under unsafe conditions; nearly all unsafe abortions (95\%) occur in developing countries (WHO 2007). ${ }^{3}$

The WHO has explained that almost all abortion related deaths are preventable when performed by a qualified 
provider using correct techniques under sanitary conditions (WHO 2003). ${ }^{4}$

In this study, we examine the safety and efficacy of manual vacuum aspiration (MVA) over that of electrical vacuum aspiration (EVA). Looking for a safer device, that could be placed in the hands of a Primary Health Centre Medical Officer or even a Lady Health Visitor, the MVA technique has evolved. Its working principle is the same as EVA. It carries not only chances of less blood loss, pain and injuries but also the great advantage of being operated manually and thus can be performed in an area where there is less or no electricity. It is a low tech procedure hence can be operated by primary health care providers. The present study compares MVA and EVA as the method for first trimester MTP in terms of efficacy, blood loss, duration, acceptability and complications.

\section{METHODS}

The study was conducted in the postpartum center and Department of Gynecology and Obstetrics, Cuttack. A total 200 patients were studied of which 100 patients underwent MVA and remaining 100 EVA. Patient selection and type of analgesia used was done randomly. Analgesia types used were paracervical block (PCB) (5 $\mathrm{ml}$ lignocaine $0.5 \%$ ) and intramuscular injection of pentazocine $30 \mathrm{mg}$ and injection promethazine $25 \mathrm{mg}$.

\section{Exclusion criteria}

Gestational age $>12$ week, spontaneous abortion, uterine malformation, associated fibroid uterus, suspected molar pregnancy, missed abortion, previous cesarean section and other pelvic pathology like pelvic inflammatory disease and endometriosis.

Preliminary investigations done were hemoglobin estimation and blood grouping and $\mathrm{Rh}$ typing. In both procedures informed written consent was taken and patient counseling was done.

In MVA (1) vacuum was created in $60 \mathrm{~mL}$ double valve MVA syringe i.e., the syringe was charged. (2) Uterus was re-evaluated by bimanual examination. (3) The size of the cannula was selected (varying from $4 \mathrm{~mm}$ to 12 $\mathrm{mm}$ ) to snugly fit in the cervical canal. (4) Using no touch technique, the cannula was inserted through the cervix towards the fundus. (5) The charged syringe was attached to the cannula and the pinch valves released allowing the vacuum to get transferred to the uterine cavity. (6) Contents of the uterus were evacuated by using rotatory or back and forth movements of the cannula. (7) Appearance of red-pink foam or bubbles, absence of more products getting aspirated, a gritty sensation as the cannula passes over the uterine walls, and a feel of the uterus contracting around the cannula were considered as signs of completeness of the procedure.
In EVA (1) Uterus was re-evaluated by bimanual examination. (2) Various parts of aspiration apparatus were connected in a way that they form a continuous system: i.e., one plastic pipe was connected from flask to the electric pump and another was connected from flask to the aspiration cannula. (3) The electric pump was set in action and the vacuum was read on the pressure gauge. (4) Negative pressure was set in the range of $0.4-0.8$ $\mathrm{kg} / \mathrm{m}^{2}$. (5) Cervical dilatation done in almost all cases. (6) Aspiration cannula chosen and passed gently through the cervical canal and into the endometrial cavity. (7) The system was started and in few minutes the products of conception were aspirated into the aspiration flask. (8) The cannula was turned around $180^{\circ}$ on its longitudinal axis and to and fro movement. It was taken out once or twice, allowing the aspirated air to compress the material through the connecting pipes into the aspirated flask. (9) Signs of completion are similar as in MVA.

The evacuated material was sent for histopathological study; inspected for chorionic villi and also the amount of blood loss and total time taken were estimated in both the groups. Intra and post-operative pain was assessed by visual analog scale (VAS).

Patients were discharged after 4 hours of observation, after advising oral antibiotics and analgesic. Those who underwent laparoscopic tubal ligation with MVA/EVA were also discharged after 4 hours. All patients were asked to come for follow-up after 1 week and were given family planning advice. Data analysis was done by SPSS software.

\section{RESULTS}

The baseline data in both MVA and EVA were compared to see if both the groups were identical.

Table 1 show that the majority of patients in both study groups were in the age group of 20-29 years. As per Tables 2 and 3 the mean time in minutes required for the MVA procedure was $8.69 \pm 2.444$ and that for EVA was $7.77 \pm 1.830$ with $P$ value 0.003 , which is statistically significant. Mean time taken in each gestational group was calculated and compared. $P$ value for $6-8$ weeks gestational age is 0.322 which is not statistically significant, but for 8-10 weeks and 10-12 weeks gestational age the $P$ values are $<0.003$ which is statistically significant. Time consumed in repeated emptying of MVA syringe in higher gestational period due to its limited capacity of $60 \mathrm{ml}$ may be a contributing factor for increased time consumption in this procedure. The mean blood loss is $40.21 \pm 10.73 \mathrm{ml}$ in MVA vs. $44.88 \pm 11.29 \mathrm{ml}$ in EVA group. This is not clinically important as both the procedures are associated with very low blood loss but it is statistically significant with $P<0.003$. There was no case of major hemorrhage requiring blood transfusion. In MVA group increased bleeding $(>60 \mathrm{ml})$ was observed in 5 cases which belonged to 10-12 weeks GA whereas in EVA group, 3 
cases from 8-10 weeks and 4 cases from 10 to 12 weeks had increased bleeding during the procedure. The mean hospital stay in this study in hours is $4.05 \pm 0.219$ for MVA and $4.64 \pm 0.785$ for EVA with $P<0.0001$, which is highly significant.

Table 1: Demographic and baseline parameters.

\begin{tabular}{|llll|}
\hline Parameters & $\begin{array}{l}\text { MVA } \\
(\boldsymbol{n}=\mathbf{1 0 0})\end{array}$ & $\begin{array}{l}\text { EVA } \\
(\boldsymbol{n}=\mathbf{1 0 0})\end{array}$ & $\begin{array}{l}\boldsymbol{P} \\
\text { value }\end{array}$ \\
\hline Age & $27.7 \pm 4.75$ & $28.31 \pm 4.73$ & 0.422 \\
\hline Rural/urban & $59 / 41(\%)$ & $63 / 37(\%)$ & \\
\hline Illiterate & $10 \%$ & $10 \%$ & \\
\hline SES (low) & $39 \%$ & $40 \%$ & \\
\hline Gravida/para & & & 0.635 \\
\hline Primi/multi $(\%)$ & $32 / 68$ & $28 / 72$ & 0.832 \\
\hline $\begin{array}{l}\text { Mean gestational } \\
\text { age (in weeks) }\end{array}$ & $8.16 \pm 2.02$ & $8.10 \pm 1.977$ & \\
\hline $\begin{array}{l}\text { MVA=Manual vacuum aspiration, } \\
\text { aspiration, SES=Socio-economic strata }\end{array}$ & vacuum \\
\hline
\end{tabular}

Table 2 shows women's reports of overall satisfaction when assessed at their follow-up visits. 90\% (92\% in MVA vs. $88 \%$ in EVA) of women indicated that they were satisfied with their experience, would choose the same method again and would recommend it to a friend. $8 \%$ in MVA and $12 \%$ in EVA group were unsatisfied with the procedure used with $P=0.816$. Hence there is no significant difference in satisfaction reported by the cases in both procedures. $8 \%$ of cases in MVA and $10 \%$ of cases in EVA group reported pain as the cause of dissatisfaction with $P=0.816$ which is statistically insignificant. However none in MVA vs. $12 \%$ cases in EVA group reported noise botheration as the cause of dissatisfaction with $P=0.03$, which is statistically significant.

Table 2: Parameters studied.

\begin{tabular}{|llll|}
\hline Parameters & $\begin{array}{l}\text { MVA } \\
(\boldsymbol{n}=\mathbf{1 0 0})\end{array}$ & $\begin{array}{l}\text { EVA } \\
(\boldsymbol{n}=\mathbf{1 0 0})\end{array}$ & $\begin{array}{l}\boldsymbol{P} \\
\text { value }\end{array}$ \\
\hline $\begin{array}{l}\text { Mean time } \\
\text { required }\end{array}$ & $8.69 \pm 2.44$ & $7.77 \pm 1.83$ & 0.003 \\
\hline $\begin{array}{l}\text { Mean blood } \\
\text { loss (ml) }\end{array}$ & $40.21 \pm 10.739$ & $44.88 \pm 11.296$ & 0.003 \\
\hline $\begin{array}{l}\text { Hospital } \\
\text { stay (hours) }\end{array}$ & $4.05 \pm 0.219$ & $4.64 \pm 0.785$ & 0.001 \\
\hline $\begin{array}{l}\text { Patient satisfaction } \\
\text { Satisfied }\end{array}$ & $92 \%$ & \\
\hline Dissatisfied & $88 \%$ & 0.816 \\
\hline \begin{tabular}{l} 
Pain \\
\hline Noise
\end{tabular} & $0 \%$ & $12 \%$ & 0.816 \\
\hline $\begin{array}{l}\text { MVA=Manual } \\
\text { aspiration }\end{array}$ & vacuum aspiration, & EVA=Electrical & vacuum \\
\hline
\end{tabular}

Table 4 shows out of the 200 study subjects, preoperative analgesia in the form of PCB or intramuscular sedation (IMS) was given randomly. PCB was given in $52 \%$ of cases and IMS in $48 \%$ of cases with $P=0.777$.
Hence both groups are comparable. Intra operatively majority i.e. $65.5 \%(78.88 \%$ in PCB vs. $51 \%$ in IMS) reported no pain. Applying Pearson Chi-square $\left(\chi^{2}\right)$ test the $P<0.0001$. Hence the differences between both groups are highly significant. During the post-operative period 93.3\% in PCB group vs. $62.5 \%$ in IMS group reported no pain with $P<0.0001$, which is also highly significant.

Table 3: Distribution of study subjects according to gestational age (weeks) and time taken (minutes).

\begin{tabular}{|llllll|}
\hline $\begin{array}{l}\text { Gestational } \\
\text { age in } \\
\text { weeks }\end{array}$ & $\begin{array}{l}\text { MVA } \\
\text { No. }\end{array}$ & $\begin{array}{l}\text { Mean } \\
\text { time } \\
\text { taken in } \\
\text { minutes }\end{array}$ & No. & $\begin{array}{l}\text { Mean } \\
\text { time } \\
\text { taken in } \\
\text { minutes }\end{array}$ & $\begin{array}{l}\boldsymbol{P} \\
\text { value }\end{array}$ \\
\hline $6-8$ & 34 & 6.1 & 34 & 6.47 & $>0.05$ \\
\hline $8-10$ & 53 & 9.5 & 54 & 7.8 & $<0.005$ \\
\hline $10-12$ & 13 & 12.3 & 12 & 11.3 & $<0.005$ \\
\hline Total & 100 & \multicolumn{5}{c|}{100} \\
\hline $\begin{array}{l}\text { MVA=Manual } \\
\text { aspiration }\end{array}$ & vacuum & aspiration, EVA=Electrical & vacuum \\
\hline
\end{tabular}

Table 4: Anesthesia/analgesia given.

\begin{tabular}{|c|c|c|c|}
\hline Parameters & PCB & IMS & $P$ value \\
\hline MVA/EVA & $51 \% / 53 \%$ & $49 \% / 47 \%$ & 0.777 \\
\hline \multicolumn{4}{|c|}{ Intraoperative } \\
\hline No pain & $78.8 \%$ & $51 \%$ & $<0.0001$ \\
\hline \multicolumn{4}{|c|}{ Post-operative } \\
\hline No pain & $93.3 \%$ & $62.5 \%$ & $<0.0001$ \\
\hline $\begin{array}{l}\text { MVA=Manual } \\
\text { aspiration, IN } \\
\text { block }\end{array}$ & $\begin{array}{l}\text { um aspirat } \\
\text { tramuscular }\end{array}$ & $\begin{array}{l}\mathrm{EVA}=\mathrm{Elec} \\
\text { dation, } \quad \mathrm{PC}\end{array}$ & $\begin{array}{l}\text { cal vacuun } \\
\text { Paracervica }\end{array}$ \\
\hline
\end{tabular}

Table 5 demonstrates that the complications during the procedure are rare except for three cases of increased bleeding and one case of vasovagal attack in EVA group. There was no case of massive hemorrhage requiring blood transfusion in both groups. There was no major complication in the MVA group. Applying Pearson's Chi-square test, the $P>0.05$, which is not statistically significant. During follow up at 7 days, lower abdominal pain (6 cases) was the commonest complaint, noted in both procedures followed by increased bleeding (4 cases), which was found more in association with those who had immediate $\mathrm{Cu}-\mathrm{T}$ insertion. The $P>0.05$; this is statistically insignificant. Incomplete evacuation was noted in both procedures for which re-exploration and evacuation had to be done. $3 \%$ of MVA and $2 \%$ of EVA had incomplete evacuation $(P>0.05$ is statistically insignificant). In the present study, MVA was effective in 97\% and EVA in $98 \%$ cases. Thus, the two procedures did not show much difference as far as their effectiveness is concerned. 
Table 5: Distribution of study subjects according to complication.

\begin{tabular}{|c|c|c|c|}
\hline Complication & MVA & EVA & $P$ value \\
\hline \multicolumn{4}{|l|}{ During procedure } \\
\hline Increased bleeding & 0 & 3 & \multirow{4}{*}{$>0.05$} \\
\hline Uterine perforation & 0 & 0 & \\
\hline Cervical injury & 0 & 0 & \\
\hline Vasovagal attack & 0 & 1 & \\
\hline \multicolumn{4}{|l|}{ During follow-up } \\
\hline Pain abdomen & 2 & 4 & \multirow{4}{*}{$>0.05$} \\
\hline Excess bleeding & 2 & 2 & \\
\hline Incomplete evacuation & 3 & 2 & \\
\hline Total & 7 & 12 & \\
\hline $\begin{array}{l}\text { MVA=Manual vacuum } \\
\text { vacuum aspiration }\end{array}$ & & & \\
\hline
\end{tabular}

\section{DISCUSSION}

In our study, patients were in the age group of 20-29 years. Kamel et al. ${ }^{5} 2011$ reported that majority of cases in their study were in the age group of 20-30 years. Westfall et al., ${ }^{6}$ also reported that majority of the MTP seekers were from 20 to 29 years age group (63.6\%). Multiparous women constituted maximum number of patients in both study groups. Kamel et al. ${ }^{5}$ in 2011 reported that majority i.e., $90.5 \%$ cases were multiparous. All the cases were married women admitted for first trimester MTP. The median gestational age was 8-10 weeks for both procedures in this study. Westfall et al. ${ }^{6}$ studied MVA on 1677 patients where majority were up to 10 weeks gestation with only 10 patients i.e., $0.6 \%$ between 10 and 12 weeks. The operating time for MVA was significantly longer than EVA in our study. Similar observations were made by Wen et al. ${ }^{7}$ in BJOG 2007 in the meta analysis of 10 studies with a gestational age of less than 50 days and by Nasira et al. ${ }^{8}$ in 2011 (Operating time $(\mathrm{min})$ mean \pm SD $10.71 \pm 2.770$ for MVA and 9.59 \pm 2.880 for EVA, $P<0.01)$.

The mean blood loss in ml was significantly higher in EVA group compared to patients in MVA group in our study. Goldberg et al. ${ }^{9}$ found that although blood loss was apparently lower with MVA, the difference between estimated blood loss of $35 \mathrm{ml}$ and $42 \mathrm{ml}$ was not clinically important and both procedures were associated with very low blood loss i.e. $35.4 \pm 16.8 \mathrm{ml}$ and $41.6 \pm$ $18.2 \mathrm{ml}$; however their $P<0.001$, which was statistically significant. Nasira et al. ${ }^{8}$ in 2011 found that the mean \pm SD blood loss was $62.08 \pm 32.190$ in MVA and $75.71 \pm$ 35.532 in EVA, the $P<0.008$. The mean hospital stay was significantly lower in the MVA group in our study. Nasira et al. ${ }^{8}$ in 2011 found that the mean hospital stay was significantly shorter in MVA group $12.26 \pm 6.97$ hours vs. $19.54 \pm 7.59$ hours in EVA group.

Wen et al. in $2007^{7}$ reported that there were no statistical differences for participants' satisfaction with the method of MVA vs. EVA and participants' preference. Dean et al. $^{10}$ in 2003 reported that there were no significant differences in pain levels or satisfaction reported by patients; however, significantly more women in the EVA group were bothered by noise $(19 \%$ vs. $2 \%, P=0.03)$. Milingos et al. ${ }^{11}$ in 2009 reported high acceptability of the procedure and $98 \%$ of women were satisfied with the procedure. In our study, PCB was found to provide better pain relief than IMS. Tekle et al. ${ }^{12}$ in 2002 reported pain relief using paracervical nerve block with $1 \%$ lignocaine injection in patients undergoing uterine evacuation by MVA for incomplete abortion. The untreated group experienced significantly more pain than the treated group, especially lower abdominal pain and backache. In our study, the effectiveness in both groups was comparable. Goldberg et al. ${ }^{9}$ in 2004 comparing MVA and EVA for first trimester abortion reported that there was overall, no difference in the rate of uterine reaspiration with MVA or EVA. Helen Kamel et al. in $2011^{5}$ reported that there was no significant difference in complications between MVA and EVA.

\section{CONCLUSIONS}

In the present study, MVA was superior in terms of significantly less blood loss and shorter hospital stay. Intra and post-operative pain assessment by visual analog scale (VAS) showed a significant difference with type of pre-operative analgesia used. Based on the finding of this study, any patient undergoing vacuum aspiration for first trimester MTP should be given PCB as it is costeffective, easy to perform and with less side-effects. There was no significant difference in complication rates in both procedures. In the present study, MVA was effective in $97 \%$ and EVA $98 \%$ cases, thus the two procedures did not show much difference as far as their effectiveness is concerned.

MVA is a safe and effective alternative to traditional electric vacuum aspiration. It is also relatively easy to perform and requires simple training for the health care provider. The manual aspiration equipment is inexpensive. Its simplicity of use and the proof that MVA has a safety and efficacy profile similar to that of EVA, could increase the number of physicians who offered abortions to their patients. Another important aspect is that MVA is a simple, safe effective procedure. Its portability and low-cost make it a technique best suited for the infrastructure in rural areas. MVA is a promising method compared to EVA which can be practiced widely in rural areas where access to medical facilities are limited, high-tech equipments are not available, erratic power supply and poor maintenance of instruments. The judicious use of MVA comes with a promise to make early abortions safe and easily accessible to women of both rural and urban societies belonging to any socioeconomic strata.

Funding: No funding sources

Conflict of interest: None declared

Ethical approval: The study was approved by the institutional ethics committee 


\section{REFERENCES}

1. Banerjeea SK, Andersenb KL, Warvadekara J. Pathways and consequences of unsafe abortion: A comparison among women with complications after induced and spontaneous abortions in Madhya Pradesh, India. Int J Gynecol Obstet. 2012;118(Suppl 2):S113-20.

2. WHO. The Prevention and Management of Unsafe Abortion. Report of a Technical Working Group. Geneva. WHO, 1992. Available at: whqlibdoc.who.int/hq/1992/WHO_MSM_92.5.pdf.

3. WHO. Unsafe Abortion: Global and Regional Estimates of the Incidence of Unsafe Abortion and Associated Mortality in 2003. 5th ed. Geneva: WHO; 2007.

4. WHO. Safe Abortion: Technical and Policy Guidance for Health Systems. 5th ed. Geneva: WHO; 2003: 106.

5. Kamel H, Sebanti G, Rekha D. Manual vacuum aspiration and electrical vacuum aspiration - A comparative study for first trimester MTP. J Obstet Gynecol India. 2011;61:53-6.

6. Westfall JM, Sophocles A, Burggraf H, Ellis S. Manual vacuum aspiration for first-trimester abortion. Arch Fam Med. 1998;7:559-62.

7. Wen J, Cai QY, Deng F, Lia YP. Manual versus electric vacuum aspiration for first-trimester abortion: A systematic review. BJOG. 2007;115:513.
8. Nasira T, Mahmud G, Fatima S, Sultana M. Manual vacuum aspiration: a safe and cost-effective substitute of Electric vacuum aspiration for the surgical management of early pregnancy loss. J Pak Med Assoc. 2011;61:149-53.

9. Goldberg AB, Dean G, Kang MS, Youssof S, Darney PD. Manual versus electric vacuum aspiration for early first-trimester abortion: A controlled study of complication rates. Obstet Gynecol. 2004;103:101-7.

10. Dean G, Cardenas L, Darney P, Goldberg A. Acceptability of manual versus electric aspiration for first trimester abortion: A randomized trial. Contraception. 2003;67:201-6.

11. Milingos DS, Mathur M, Smith NC, Ashok PW. Manual vacuum aspiration: A safe alternative for the surgical management of early pregnancy loss. BJOG. 2009;116:1268-71.

12. Tekle GE, Ruminjo JK, Sekadde-Kigondu C. Pain relief using paracervical block with $1 \%$ lignocaine injection in patients undergoing uterine evacuation by manual vacuum aspiration of uterus. East Afr Med J. 2002;79:530-4.

DOI: $10.5455 / 2320-1770.1 j \mathrm{rcog} 20140327$

Cite this article as: Samal SK, Rathod S, Padhi M. A comparative study between manual vacuum aspiration and electrical vacuum aspiration for the first trimester medical termination of pregnancy. Int J Reprod Contracept Obstet Gynecol 2014;3:13943. 